\title{
A Simple Method to Prepare Oligonucleotide-Conjugated Antibodies and Its Application in Multiplex Protein Detection in Single Cells
}

\author{
Haibiao Gong, Ilona Holcomb, Aik Ooi, Xiaohui Wang, Daniel Majonis, Marc A. Unger, \\ Ramesh Ramakrishnan*
}

Fluidigm Corporation, South San Francisco, CA 94080 USA

Running title: Oligonucleotide-conjugated antibodies for protein detection

*Correspondence: Fluidigm Corporation, South San Francisco, CA 94080 USA; Tel: (650)

266-6084; Email: ramesh.ramakrishnan@fluidigm.com 


\section{Fig. S1}

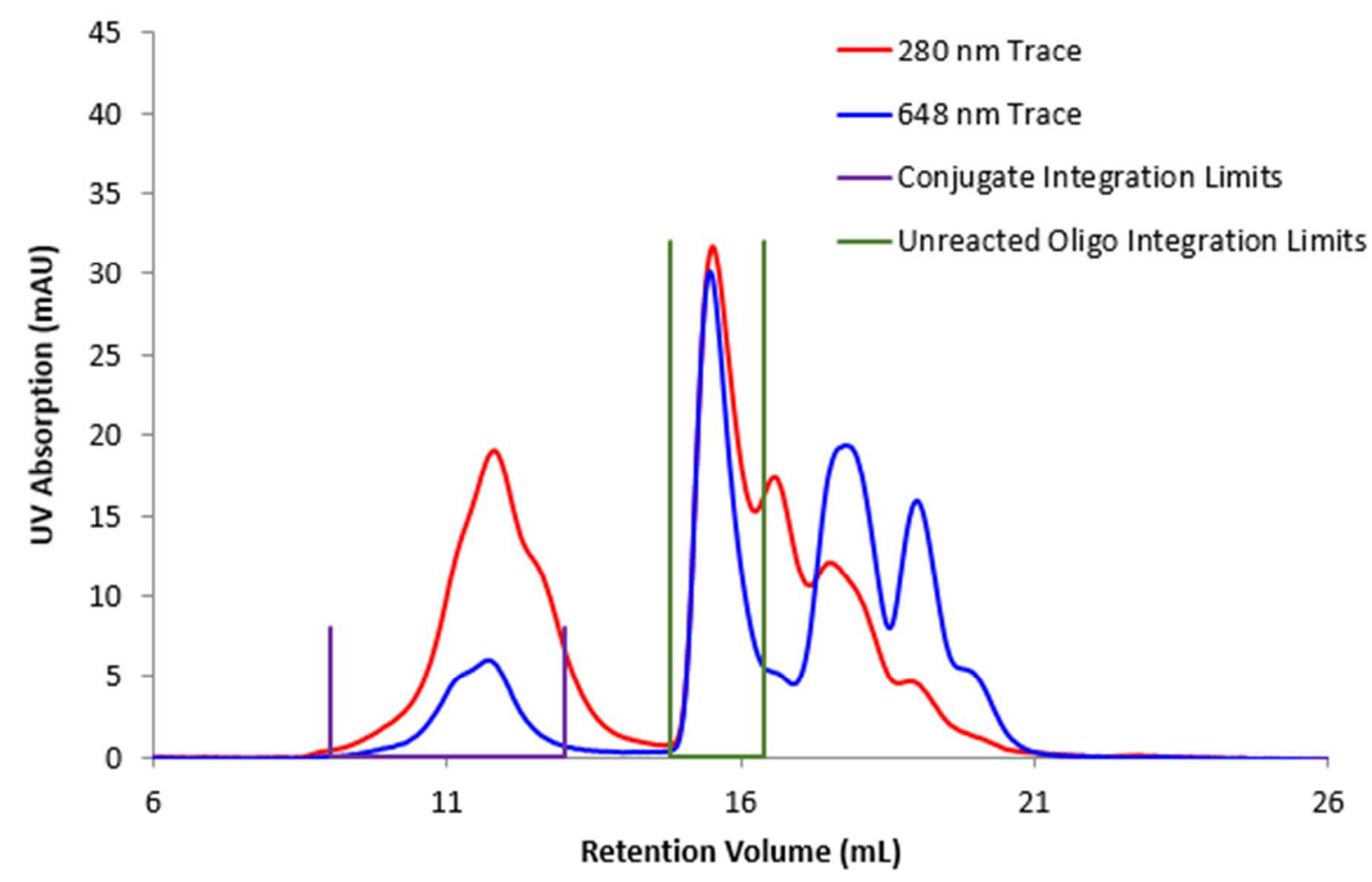

Fig. S1. FPLC determination of number of oligonucleotides conjugated to the antibody. A Cy5-

modified oligonucleotide was conjugated to a goat anti-IgY antibody, and without purification was analyzed by size-exclusion FPLC. The conjugated portion of oligonucleotide was represented by the peak at a retention volume of $11.8 \mathrm{~mL}$; the unreacted portion of oligonucleotide was represented by the peak at a retention volume of $15.5 \mathrm{~mL}$. The number of oligonucleotides conjugated to the antibody was estimated using a) the known ratio of oligonucleotide to antibody used in the conjugation reaction, and b) the areas under the two peaks ( $648 \mathrm{~nm}$, blue curve); this number was found to be about 1.2. A number of peaks in the $648 \mathrm{~nm}$ trace were observed at higher retention volume; these may represent degradation products of the oligonucleotide. 